

Prosiding Seminar Nasional NCIET Vol.1 (2020) B79-B88

$1^{\text {st }}$ National Conference of Industry, Engineering and Technology 2020, Semarang, Indonesia.

\title{
OPTIMASI PADA COOLING TOWER MENGGUNAKAN RESPONSE SURFACE METHODOLOGY
}

\author{
Elyvia Anggraini, Saiful Anwar, dan Bayu Rudiyanto* \\ Jurusan Teknik, Politeknik Negeri Jember \\ Jl. Mastrip, Kotak Pos164, Jember, 68121 \\ *E-mail: bayu_rudianto@polije.ac.id
}

\begin{abstract}
Abstrak
Analisis Eksergi dan Optimasi cooling Tower Induced Draft Crossflow di Pembangkit Listrik Tenaga Panas Bumi Kamojang Indonesia telah dilakukan dengan Response Surface Method dengan jenis rancana Box Behnken Design untuk meng evaluasi kinerja cooling tower. Hasil analisis data pada cooling tower selama 1 bulan di PLTP Kamojang POMU (Power generation Operation and Maintenance service Unit) didapatkan data dari logsheet dan menggunakan head balance untuk menghitung analisis eksergi pada cooling tower yang menghasilkan rata-rata jumlah eksergi masuk sebelum optimasi sebesar $12339,55 \mathrm{~kW}$, hasil rata-rata jumlah eksergi keluar sebesar 6305,671 kW, hasil rata-rata irreversibitas sebesar $6033.879 \mathrm{~kW}$ dengan nilai efisiensi eksergi sebesar 51,10\% dan didapatkan rata-rata jumlah eksergi masuk setelah optimasi sebesar 13426,67 kW, hasil rata-rata jumlah eksergi keluar sebesar $8358 \mathrm{~kW}$, hasil rata-rata irreversibitas sebesar 5068,67 kW dengan nilai efisiensi eksergi sebesar 62,10\%. Dari perhitungan sebelum optimasi dan setelah optimasi mengalami penurunan pada efisiensi eksergi pada cooling tower, jadi tujuan optimasi menggunakan Response Surface Method dengan jenis rancana Box Behnken Design Untuk mengoptimasi dan mengurangi nilai irreversibitas serta meningkatkan efisiensi eksergi cooling tower dan untuk mendapatkan kondisi operasi yang paling optimal dari komponen yang di optimasi.
\end{abstract}

Kata Kunci: Cooling tower; energi; eksergi; irreversibilitas; optimasi.

\section{PENDAHULUAN}

Indonesia merupakan negara yang mempunyai sumber daya alam yang sangat melimpah, salah satunya adalah panas bumi yang diolah dan digunakan sebagai pembangkit listrik tenaga panas bumi. PT. Indonesia Power Kamojang POMU merupakan pembangkit listrik tenaga panas bumi pertama di indonesia yang memproduksi listrik sebesar $140 \mathrm{MW}$, secara umum proses produksi uap (steam) digunakan sebagai penggerak turbin dengan memanfaatkan panas yang ada dalam perut bumi. Cooling tower sangat dibutuhkan oleh industri untuk efisiensi dan konversi energi dimana digunakan untuk alat atau unit sirkulasi air pendingin. Fungsi Cooling tower adalah untuk mendinginkan air hasil kondensasi sehingga dapat digunakan kembali untuk proses kondensasi, mendinginkan alat bantu inter- 
after kondensor dan diinjeksikan kembali ke dalam perut bumi. Selain itu Cooling tower juga berfungsi untuk pembuangan akhir yang berupa uap ke atmosfer. PLTP Kamojang selama beroperasi 30 tahun mengalami penurunan kinerja dan efisiensi pada beberapa komponen utama pembangkit, salah satunya adalah Cooling tower. Agar memperoleh kapasitas yang optimal maka diperlukan efisiensi yang baik dari produksi dengan memperhatikan kinerja Cooling tower sehingga berakibat banyak terjadi kerugian energi selama proses konversi energi, upaya yang dilakukan dengan pendekatan termodinamika menggunakan analisis eksergi dan dioptimasi menggunakan Response Surface Method yang bertujuan untuk memberikan kemudahan dalam menentukan kondisi yang optimum dan mendapatkan hasil target respon pada kondisi yang di inginkan. Response Surface Method merupakan kumpulan statistika dan matematika teknik yang digunakan untuk mengembangkan, meningkatkan, dan mengoptimalkan proses dimana respon dipengaruhi oleh beberapa faktor (variabel independen). Pada penelitian ini dilakukan optimasi pada Cooling tower dengan menggunakan analisis eksergi di Pembangkit Listrik Tenaga Panas Bumi (PLTP) PT.Indonesia Power Kamojang POMU Unit 2 dengan langkah optimasi untuk meningkatkan kinerja dan efisiensi Cooling tower menggunakan Response Surface Method dengan jenis rancangan Box Behnken Design. Persamaan analisis eksergi dikembangkan menggunakan simulasi Engineering Equation Solver (EES) yang didasari hukum termodinamika.

\section{METODE PENELITIAN}

Penelitian dilakukan di PT. Indonesia Power Kamojang POMU Unit 2 tepatnya di Kabupaten Bandung, Jawa Barat. Sebuah perusahaan yang bergerak dibidang pembangkit listrik tenaga panas bumi (PLTP).

\section{Metode Analisis}

Analisis energi dan proses konversi energi dalam termodinamika pada cooling tower process. Cooling tower berfungsi untuk mendinginkan kondensat dari pompa MCWP agar selanjutnya kondensat ini dapat disirkulasikan sebagai air pendingin. Cooling tower ini menggunakan kipas untuk mengalirkan udara sebagai pendingin. Cooling tower PLTP Kamojang adalah jenis mechanical draft cross flow cooling tower air panas dari kondensor disemprotkan pada struktur kayu yang berlapis-lapis yang disebut fill. Pada saat air mengalir melalui fill, perpindahan panas akan terjadi dari air panas ke udara atau kontak langsung dengan udara, air hasil pendinginan ditampung di cold basin. Air kemudian dipompakan 
kembali ke dalam kondensor untuk proses kondensasi. Persamaan energi pada cooling tower dengan mengasumsikan aliran stabil dan adiabatic sebagai berikut :

$$
\dot{m}_{\text {cond }} \cdot h_{\text {cond }}+\dot{m}_{a} \cdot h_{a}=\dot{m}_{c w} \cdot h_{c w}+\dot{m}_{d} \cdot h_{d}
$$

\section{Analisis Eksergi}

Metode analisis eksergi dapat menunjukkan kualitas dan kuantitas kerugian panas serta lokasi kehilangan eksergi tersebut. Sehingga besar kasus ketidaksempurnaan termodinamika tidak dapat dideteksi dengan analisis energi. Persamaan kerja aktual dan kerja reversibel sering diformulasikan dalam persamaan fungsi eksergi baik untuk sisteml terbuka dan tertutup dengan persamaan sebagai berikut :

$$
\mathrm{E}=\dot{\mathrm{m}}\left(\mathrm{h}-\mathrm{h}_{0}\right)-\mathrm{T}_{0}\left(\mathrm{~s}-\mathrm{s}_{0}\right)
$$

Sedangkan persamaan Efisiensi Eksergi pada cooling tower dapat dirumuskan sebagai berikut

$$
\text { Efisiensi Eksergi }=\frac{\text { Eksergi output }}{\text { Eksergi } \text { input }} \times 100 \%
$$

Analisis dimulai penentuan sifat termodinamika berdasarkan hasil pengambilan data yang meliputi : suhu udara masuk dan keluar, suhu air masuk dan keluar, laju aliran massa masuk dan keluar. Komponen akhir yang akan dianalisis adalah kinerja cooling tower sesuai dengan pendekatan eksergi, untuk melihat seberapa besar efisiensi eksergi pada cooling tower kemudian dioptimalkan menggunakan Response Surface Method.

\section{Metode Optimasi}

Optimasi merupakan pencarian nilai-nilai variabel yang dianggap optimal, efektif dan efisien untuk mencapai hasil yang diinginkan dengan tujuan untuk memilih kondisi dari beberapa variabel input yang disebut dengan variabel independen untuk mendapatkan kondisi output yang optimum pada variabel respon. Jika respon dimodelkan secara baik dengan fungsi linier dari variabel-variabel independe $\mathrm{x}_{\mathrm{i}}$. Fungsi dari model 1 adalah :

$$
\mathrm{Y}=\beta_{0}+\beta_{1} \mathrm{x}_{1}+\beta_{2} \beta_{2}+\ldots+\beta_{\mathrm{k}} \mathrm{x}_{\mathrm{k}}+\varepsilon
$$

Persamaan tersebut merupakan sebuah model regresi linier multiple dengan dua variabel bebas. $\beta_{1}$ dan $\beta_{2}$ merupakan koefisien regresi persial dimana $\beta_{1}$ mengukur perubahan y setiap perubahan unit $\mathrm{x}_{1}$ dan $\beta_{2}$ mengukur perubahan y setiap perubahan unit $\mathrm{x}_{2}$. Selanjutnya pada keadaan mendekati respon, model orde dua atau lebih biasanya disyaratkan untuk mengaproksimasi respon karena adanya lengkungan dalam permukaannya. Fungsi model orde 2 adalah :

$$
\mathrm{Y}=\beta_{0}+\sum_{i}^{k}=1 \quad \beta_{\mathrm{i}} \mathrm{x}_{\mathrm{j}}+\sum_{i}^{k}=1 \quad \beta_{\mathrm{ii}} \mathrm{x}_{\mathrm{i}}^{2}+\sum \sum i<j \quad \beta_{\mathrm{ij}} \mathrm{x}_{\mathrm{ij}} \mathrm{x}_{\mathrm{j}}+\varepsilon
$$




\section{HASIL DAN PEMBAHASAN}

\section{Analisis Eksergi pada Cooling Tower}

Diperoleh data yang digunakan dalam penelitian ini meliputi data waktu operasi Cooling tower dengan menghitung laju eksergi masuk, laju eksergi keluar, irreversibilitas dan efisiensi eksergi yang terjadi sebelum dilakukan optimasi dan setelah dilakukan optimasi.

Tabel 1. data laju eksergi masuk, laju eksergi keluar, irreversibilitas dan efisiensi eksergi pada Cooling tower sebelum dilakuakan optimasi menggunakan Response Surface Method No eksergi input (kW) eksergi output $(\mathrm{kW}) \quad$ Irreversibilitas $(\mathrm{kW}) \quad$ efisiensi eksergi (\%)

\begin{tabular}{lllll}
\hline 1 & 63339,55 & 6305,671 & 6033,879 & 51,10 \\
\hline
\end{tabular}

Sumber: Dokumen Pribadi Peneliti, Tahun 2020

Berdasarkan Tabel 1. diketahui bahwa besar eksergi dapat menunjukkan seberapa besar ketersediaan energi pada sistem pembangkit. Pada data diatas didapatkan sebelum dilakukan optimasi menggunakan Response Surface Method dengan nilai rata-rata eksergi masuk cooling tower sebesar 12339,55 kJ/s sedangkan nilai rata-rata eksergi keluar sebesar 6305,671 Kj/s. Jadi nilai eksergi masuk lebih besar dibandingkan nilai eksergi keluar dikarenakan akan selalu ada eksergi yang hilang atau keluar sistem atau pemusnahan akibat konsumsi peningkatan entopi. Nilai rata-rata irreversibilitas sebesar 6033,879 kW karena di pengaruhi oleh massa aliran dan suhu lingkungan yang masuk pada cooling tower sehingga besar efisiensi eksergi pada cooling tower sebesar 51,10\%.

Tabel 2. data laju eksergi masuk, laju eksergi keluar, irreversibilitas dan efisiensi eksergi pada Cooling tower setelah dilakuakan optimasi menggunakan Response Surface Method

\begin{tabular}{ccccc} 
No & eksergi input $(\mathrm{kW})$ & eksergi output $(\mathrm{kW})$ & Irreversibilitas $(\mathrm{kW})$ & efisiensi eksergi $(\%)$ \\
\hline 1 & 13426,67 & 8358 & 5068,67 & 62,10
\end{tabular}

Sumber: Dokumen Pribadi Peneliti, Tahun 2020

Berdasarkan Tabel 2. diketahui bahwa besar eksergi dapat menunjukkan seberapa besar ketersediaan energi pada sistem pembangkit. Pada data diatas didapatkan setelah dilakukan optimasi menggunakan Response Surface Method dengan nilai rata-rata eksergi masuk cooling tower sebesar 13426,67 kJ/s sedangkan nilai rata-rata eksergi keluar sebesar 8358 $\mathrm{kJ} / \mathrm{s}$. Jadi nilai eksergi masuk lebih besar dibandingkan nilai eksergi keluar dikarenakan akan selalu ada eksergi yang hilang atau keluar sistem atau pemusnahan akibat konsumsi 
peningkatan entopi. Nilai rata-rata irreversibilitas sebesar 5068,67 kW karena di pengaruhi oleh massa aliran dan suhu lingkungan yang masuk pada cooling tower sehingga besar efisiensi eksergi pada cooling tower sebesar 62,10\%.

\section{Optimasi Menggunakan Metode Box Behnken Design}

Berdasarkan analisa optimasi menggunakan Response Surface Method dengan menggunakan metode Box Behnken Desain pada pendugaan upaya optimasi menggunakan 5 faktor Box Behnken Desain dengan variable berupa Temperature Air Input (Tai), Temperature Water Input (Twi), Massa Air Input (mai), Massa Water Input (mwi), Temperature Wet Bulb Input (Twb i) serta variable respon berupa Massa Water Output (mwo), Temperature Air Output (Tao), Temperature Water Output (Two). Optimasi yang diambil dalam penelitian ini adalah mengoptimasi Laju aliran massa keluar (massa water output) dan Suhu udara keluar (temperature air output) dari cooling tower terhadap kinerja cooling tower.

Tabel 3. Range Parameter Untuk Optimasi Respon

\begin{tabular}{lcccc}
\hline \multicolumn{1}{c}{ Design Variabel (Factor) } & Coded variabels & Units & LOW & HIGH \\
\hline Suhu udara masuk (Tai) ${ }^{\circ} \mathrm{C}$ & $\mathrm{X}_{1}$ & ${ }^{\circ} \mathrm{C}$ & 18 & 21 \\
Suhu air masuk (Twi) ${ }^{\circ} \mathrm{C}$ & $\mathrm{X}_{2}$ & ${ }^{\circ} \mathrm{C}$ & 43 & 45 \\
Laju aliran massa air masuk (mwi) kg/s & $\mathrm{X}_{3}$ & $\mathrm{~kg} / \mathrm{s}$ & 3055 & 3150 \\
Laju aliran udara masuk (mai) kg/s & $\mathrm{X}_{4}$ & $\mathrm{~kg} / \mathrm{s}$ & 3100 & 3110 \\
Suhu Wet bulb masuk (Twb,i) ${ }^{\circ} \mathrm{C}$ & $\mathrm{X}_{5}$ & ${ }^{\circ} \mathrm{C}$ & 16 & 18 \\
\hline
\end{tabular}

Sumber : Data Pengujian Software Minitab 17, Tahun 2020

Berdasarkan data variabel perlakuan pada Box Behnken Design terdapat koefisien penduga model matematika output software MINITAB 17. Dari koefisien penduga dapat terlihat pengaruh laju aliran massa air yang keluar (massa water output) terhadap kinerja cooling tower dilakukan optimasi yang menghasilkan Response terbaik dengan kondisi yang optimum terdapat pada Suhu udara masuk terhadap laju aliran massa air keluar dengan nilai P-value 0,027 dan laju aliran massa udara masuk terhadap laju aliran massa air keluar dengan nilai P-value 0,033 didapatkan Lack of fit 0,04 dengan $\mathrm{R}^{2}$ yang diperoleh $91 \%$. yang terdapat pada Regression Equation yang menghasilkan model matematika orde kedua sebagai berikut :

$$
\begin{aligned}
\text { mwo }= & 4429847-1563 \text { tai }-3606 \text { twi }-111,5 \text { mwi }-2666 \text { mai }-2763 \text { twb,i }+4,79 \text { tai*tai } \\
& +2,35 \text { twi*twi }+0,01622 \text { mwi*mwi }+0,414 \text { mai*mai }+7,52 \text { twb,i*twb,i } \\
& -0,00 \text { tai*twi }+0,0316 \text { tai*mwi }+0,433 \text { tai*mai }-4,17 \text { tai*twb,i }-0,132 \text { twi*mwi } \\
& +1,25 \text { twi*mai }-4,00 \text { twi*twb,i }+0,0053 \text { mwi*mai }+0,042 \text { mwi*twb,i } \\
& +0,85 \text { mai*twb,i }
\end{aligned}
$$


plot permukaan respon dan Contour plot sebagai fungsi antara dua variabel dari tiga variabel yang diujikan akan lebih memudahkan untuk melihat pengaruh dari variabelvariabel sebagai berikut :

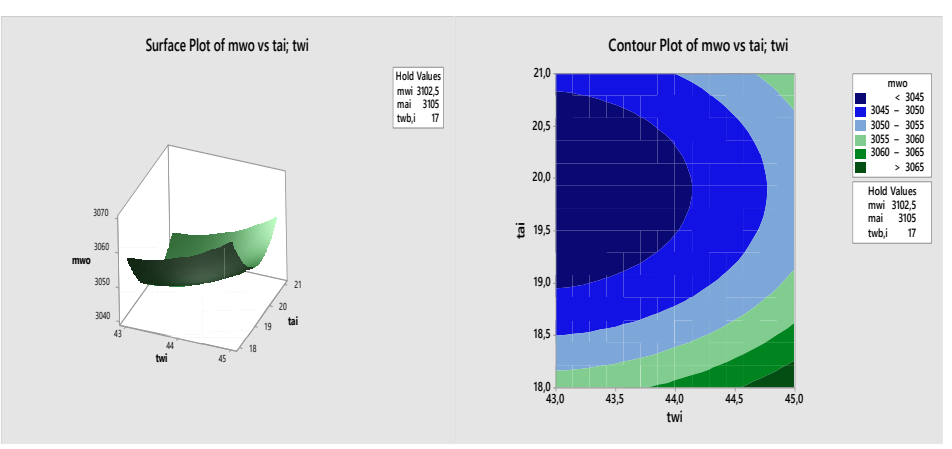

Gambar 1. Hubungan antara suhu udara masuk dengan suhu air masuk terhadap laju aliran massa air keluar

Sumber: Data Pengujian Software Minitab 17 Metode Box Behnken Design, Tahun 2020

Gambar 1. Menunjukkan hubungan antara suhu udara masuk dan suhu air masuk terhadap laju aliran massa air keluar dalam bentuk Response Surface Plot dan Contour plot. Secara visual dapat dilihat pada Contour plot Gambar 1. Terlihat bahwa nilai laju aliran massa air keluar kurang dari $3045 \mathrm{~kg} / \mathrm{s}$ interaksi suhu udara masuk dengan suhu air masuk berpengaruh terhadap laju aliran massa air keluar

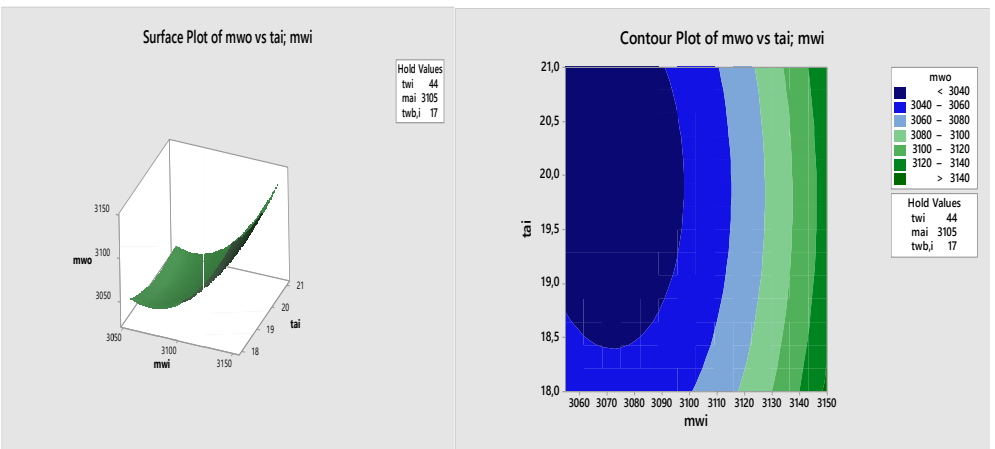

Gambar 2. Hubungan antara suhu udara masuk dengan laju aliran massa air masuk terhadap laju aliran massa air keluar

Sumber: Data Pengujian Software Minitab 17 Metode Box Behnken Design, Tahun 2020

Gambar 2. Menunjukkan hubungan antara suhu udara masuk dan suhu laju aliran massa air masuk terhadap laju aliran massa air keluar dalam bentuk Response Surface Plot dan Contour plot. Secara visual dapat dilihat pada Contour plot Gambar 2. Terlihat bahwa nilai laju aliran massa air keluar pada rentang 3040-3060 kg/s interaksi suhu udara masuk dengan laju aliran massa air masuk berpengaruh terhadap laju aliran massa air keluar. 




Gambar 3. Hubungan antara suhu air masuk dengan laju aliran massa air masuk terhadap laju aliran massa air keluar

Sumber: Data Pengujian Software Minitab 17 Metode Box Behnken Design, Tahun 2020

Gambar 3. Menunjukkan hubungan antara suhu air masuk dan laju aliran massa air masuk terhadap laju aliran massa air keluar dalam bentuk Response Surface Plot dan Contour plot. Secara visual dapat dilihat pada Contour plot Gambar 3. Terlihat bahwa nilai laju aliran massa air keluar pada rentang 3040-3060 kg/s interaksi suhu air masuk dan laju aliran massa air masuk berpengaruh terhadap laju aliran massa air keluar

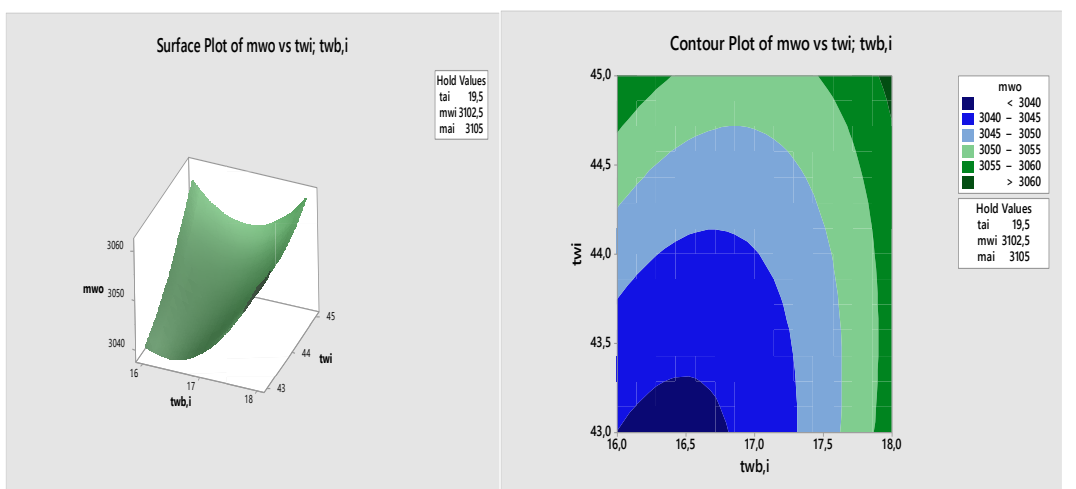

Gambar 4. Hubungan antara suhu air masuk dengan suhu wet bulb terhadap laju aliran massa air keluar

Sumber: Data Pengujian Software Minitab 17 Metode Box Behnken Design, Tahun 2020

Gambar 4. Menunjukkan hubungan antara suhu air masuk dan suhu wet bulb masuk terhadap laju aliran massa air keluar dalam bentuk Response Surface Plot dan Contour plot. Secara visual dapat dilihat pada Contour plot Gambar 4. Terlihat bahwa nilai laju aliran massa air keluar pada rentang 3040-3060 kg/s interaksi suhu air masuk dan suhu wet bulb masuk berpengaruh terhadap laju aliran massa air keluar 


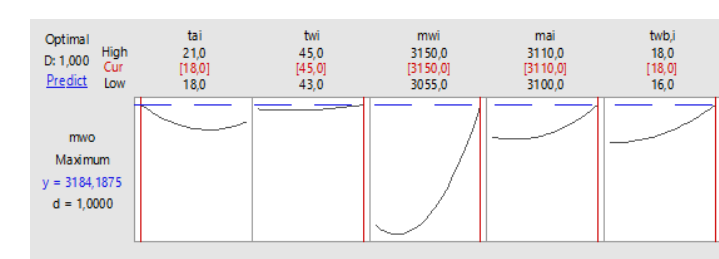

\section{Gambar 5. Response Optimizer pada Cooling Tower}

Sumber: Data Pengujian Software Minitab 17 Metode Box Behnken Design, Tahun 2020

Berdasarkan pada Gambar 5. dapat disimpulkan bahwa nilai yang optimum pada respon laju aliran massa air keluar (massa water output). Pada suhu udara keluar (temperature air output) kondisi optimal nya dititik : temperature air input pada titik $18{ }^{\circ} \mathrm{C}$, temperature water input pada titik $45{ }^{\circ} \mathrm{C}$, massa water input pada titik $3150 \mathrm{~kg} / \mathrm{s}$, massa air input pada titik $3110 \mathrm{~kg} / \mathrm{s}$, temperature wet bulb input pada titik $18{ }^{\circ} \mathrm{C}$. Jadi diprediksi responnya mencapai maksimum pada massa water output sebesar $3184,18 \mathrm{~kg} / \mathrm{s}$.

\section{KESIMPULAN}

Dari hasil analisis eksergi pada cooling tower PLTP Kamojang Unit 2, diperoleh kesimpulan sebagai berikut :

- Kehilangan eksergi masuk rata - rata pada cooling tower PLTP Kamojang unit 2 sebelum dilakukan optimasi sebesar 12339,55 kW , kehilangan eksergi keluar rata-rata pada cooling tower sebesar $6305,671 \mathrm{~kW}$, nilai rata-rata irreversibilitas pada cooling tower sebesar 6033,879 $\mathrm{kW}$ dan nilai efisiensi eksergi cooling tower sebesar 51,10\% sedangkan setelah dilakukan optimasi sebesar 13426,67 kW , kehilangan eksergi keluar rata-rata pada cooling tower sebesar $8356 \mathrm{~kW}$ dan nilai rata-rata irreversibilitas pada cooling tower sebesar 5068,67 kW dan nilai efisiensi eksergi cooling tower sebesar $62,10 \%$. Optimasi dilakukan munggunakan Response Surface Method dengan jenis rancangan Box Behnken Design.

- Response yang terbaik dengan kondisi nilai yang optimum pada respon laju aliran massa air keluar (massa water output). Pada suhu udara keluar (temperature air output) kondisi optimal nya dititik: temperature air input pada titik $18{ }^{\circ} \mathrm{C}$, temperature water input pada titik $45^{\circ} \mathrm{C}$, massa water input pada titik $3150 \mathrm{~kg} / \mathrm{s}$, massa air input pada titik $3110 \mathrm{~kg} / \mathrm{s}$, temperature wet bulb input pada titik $18^{\circ} \mathrm{C}$. jadi pada laju aliran massa air keluar (massa 
water output) diprediksi responnya mencapai maksimum pada massa water output sebesar $3184,18 \mathrm{~kg} / \mathrm{s}$.

\section{DAFTAR PUSTAKA}

Adiprana. 2015. Kamojang Geothermal Power Optimization Bazed $n$ Exergy analisis. Proceedings World Geothermal Congress. Melbourne. PT. Indonesia Power Kamojang. Ansari \& Hughes, 2016. Response Surface Method for Assessing Energy Production From Geopressured Geothermal Reservoir. Geothermal Energy. Vol 4;15DOI 10.1186/s40517-016-0057-5.

Bejan, A., G. Tsatsaronis, M. Moran. 1996. Thermal Design and Optimization. New York : John Wiley and Sons Inc.

Cengel, Y. A. and M. A. Boles. 2015. Thermodynamic an Engineering Approach $8^{\text {th }}$ Ed. New York : McGraw-hill Education.

Edwards , L.M, J. Reynold. 1982. Hanbook Of Geothermal Energy. Chapter 9 . Gulf Publishing Company

Effendi , A and Wirza, R. (2013). Perencanaan Sistem Scada Cooling Tower menggunakan Siemens step 7 dan wincc. Fakultas Teknologi Industri - Intitut Teknologi Padang, TEKNOIF 1(1), PP. 6-14.

Handoyo , Y . (2015). Analisis performa cooling tower LCT 400 pada PT. XYZ Tumban Bekasi. Jurnal Ilmiah Teknik Mesin, 3(1), PP. 38-52.

Ilvana M, S. 2009. Analisa perhitungan karakteristik dan efektivitas homon cooling tower. Universitas Diponegoro Semarang.

Illah, I. A. 2016. Analisis Eksergi Sistem Pembangkit Listrik Tenaga Panas Bumi Siklus Uap Hasil Pemisahan (Separated Steam Cycle) di PT. Indonesia Power UPJP Kamojang. Skripsi. Jurusan Teknik Politeknik Negeri Jember.

Kementrian Energi dan Sumber Daya Mineral (KESDM). 2017a. Potensi Panas Bumi Indonesia. jilid 1. Jakarta : Direktorat Pnas Bumi, Direktorat Jendral Energi Baru Terbarukan dan Konservasi Energi (Dirjen EBTKE) KESDM.

Khuri, A.L. and Mukhopadhyay, S. 2010. Response Surface Methodology, Willey Interdischip. Rev Comput Staf 2, 128-149.

Nugroho, G. 2018. Analisis Thermal pada Pembangkit Listrik Tenaga Panas Bumi PT. Indonesia Power UPJP Kamojang. Jurnal Teknik. Institut Teknologi Sepuluh November (ITS).

Mentgomer, D.C. 2001. Design and Analysis of Experimens, John Willey dan Sons Inc, New York.

Myers, R. H. 1971. Response Surface Methodology. American Journal of Operations Research, Vol 7 No. 3, May 24, 2017.

Moran, M.J. and H.N. Saphiro. 2004. Termodinamika Teknik Edisi 4 jilid 1. Jakarta : Erlangga.

Moran, M.J. and H.N. Saphiro. 2006. Fundamentals of Engineering Thermodinamics, $5^{\text {th }}$ Edition. England (GB) : John Willey.

Purwanti, dkk. 2013. Aplikasi Box Behnken Design untuk Optimasi Prameter Proses Pemesinan Bubut Magnesium AZ31. Universitas Lampung.

Rosen, M.A. 2002. Clarifying Tehermodinamic Efficiencies and Loses Via Exergy, an International Jurnal 2 (2002), 3-5. 
Rudiyanto, B., I.A. Illah, N.A. Pambudi, C. Ceng. R. Adiprana, M. Imran, L.H. Saw, R. Handogo. 2017. Preliminary Analysis of Dr-Steam Geothhermal Power Plant by Employing Exxergy Assessment Case Study in Kamojang Geothermal Power Plant, Indonesia. In Journal of Case Studies in Thermal Engineering, 10. P. 292-301.

Santoso, dkk. 2012. Analisis Eksergi pada Pembangkit Listrik Tenaga Panas Bumi UBP Kamojang Unit PLTP Darajat Jawa Barat, 134-139.

Sanyal, S . 2005. Sustainability and Renewability of Geothermal Power Capacity. Proceedings world geothermal congress. Turkey.

Shukuya. 2000. Introduction to the Concept of Exergy for Better Understanding of Low Temperature- Heading and High Temperature Cooling System. VTT Tiedotteita 2158 $: 10-14$.

Singh, K. 2017. Energy Conversion and Management 136. Indian Institute of Technology Ropar. India

Suryadarma et al, 2010. Lessons Leanerd from Kamojang Geothermal Steam field management : from the Beginning until now. Proceedings world geothermal congress. Melbourne. PT. Pertamina Geothermal Energy Kamojang.

Sung, H.P, et al, 2003. Optimasi central composite designs for fiting secod order response surface regression models. Basic Research Program of the Korea Science and Engineering Foundation. No. R01-2003-000-10220-0.

Wakil, E.L. 1992. Power Plant Technology. Institut Pembangkit Daya . Jakarta : Erlangga. 